\title{
Analysis of Existing and Development Prospects of Decision Support Systems for Evaluating Investment Projects in the Field of Enterprise Digitalization
}

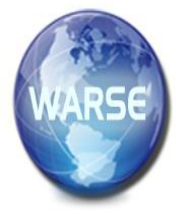

\author{
Lakhno V. A. ${ }^{1}$, Kartbayev T.S. ${ }^{2,3}$, Turginbayeva A.A. ${ }^{3}$, Alimseitova Zh. K. ${ }^{4}$, Beketova G.S. \\ ${ }^{1}$ National University of Life and Environmental Sciences of Ukraine, Ukraine, 1va964@gmail.com \\ ${ }^{2}$ Gumarbek Daukeev Almaty University of Energy and Communications, Kazakhstan, \\ kartbaev_t@mail.ru \\ ${ }^{3}$ Al-Farabi Kazakh National University, Kazakhstan, kartbaev_t@mail.ru \\ ${ }^{4}$ Gumarbek Daukeev Almaty University of Energy and Communications, Kazakhstan, \\ zhuldyz_al@mail.ru \\ ${ }^{5}$ Gumarbek Daukeev Almaty University of Energy and Communications, Kazakhstan, \\ beketova_gs@mail.ru
}

\begin{abstract}
The article provides a review and analysis of existing software development in the field of computer-based decision support (DS). It is shown that to increase the reliability of recommendations provided by analysts (decision maker - DM) in various fields, in particular, in tasks related to the evaluation of investment projects, it is necessary to make greater use of computer-based decision support systems (DSS). The article demonstrates that in order to increase the efficiency of the DS process, it is necessary to develop new models and methods for expert evaluation and appropriate software tools based on them. The essence of the proposed paradigms which perspective program developments in the field of DSS have to be based on is described. The main tasks that have to be solved in the process of synthesizing the theoretical and program-technological bases of creating the corresponding DSS toolkit in high-level languages are formulated. A general methodology of holding subsequent research stages and use of the necessary mathematical tools to achieve the ultimate goal - DSS development for evaluating investment projects in the field of enterprises digitization was proposed.
\end{abstract}

Key words: decision support, expert evaluation, investment appraisal/investment evaluation, design paradigms, models, methods, functional scheme

\section{INTRODUCTION}

The rapid development of the digital economy has significantly affected the growth in demand for modern information technologies (IT), which make it possible to process the initial information quickly and efficiently in the processes of analyzing and solving various problem tasks. Information technologies and computer-aided systems help to increase the level of management processes' information support, and have become an important factor in the successful development of many enterprises, regions and states. IT decision support (DS), necessary for investment management are one of the priorities [1] today. However, according to the results of research by many authors [2], [3], the software products (SP) market, positioned by developers as a decision support system (DSS), continues to evolve, and every year calculation of the number of SP that contribute to improving the efficiency of the DS process, by automating multiple calculations, simulation results visualization and alternative approaches comparison.

In connection with the rapid growth in the use of computer-aided DS technology, there has recently been a demand for intelligent systems designed to solve problems in various subject areas. Among the world's leading developments in the DSS market should be mentioned: Expert Choice, Super Decisions, Decision Lens, D-Sight, Promethee, and etc [4], [5].

In the article we reviewed the publications related to the use of modern DSS. It should be noted that such review cannot cover all the diversity of such systems. Besides, the review does not consider narrow-focus, specialized DSS, for example, such as medical DSS, or DSS used in fault diagnostics of technical systems (cars, computers, etc.).

The analysis of existing foreign software products in the field of DSS suggested that the development of domestic DSS in investment projects evaluation, in particular in the field of enterprise digitalization, is an important and relevant task.

\section{THE PURPOSE OF THE ARTICLE}

To review and analyze existing decision support systems that are used in investment projects evaluation, as well as the justification of paradigms for perspective DSS in this category of tasks.

In order to achieve the goal of the article it is necessary:

- to review and analyze existing DSS connected with the investment projects evaluation;

- to consider the paradigms on which promising software development should be based for decision support systems for investment projects evaluation in the field of enterprise digitalization. 


\section{REVIEW OF PRIOR STUDIES AND EXISTING DSS}

Common features that characterize all DSS architectures, regardless of the purpose, are: availability of a knowledge base (KB), a domain model (decision context and evaluation criteria), an interface for users [5], [7].

Taking into account the above-mentioned considerations, the article proposes to focus on the DSS for universal use. Mathematical support of such DSS includes the most popular modern decision-making methods based on expert data.

One of the popular and affordable in a wide range of consumers is the DSS 1000minds [7], [8], see figure 1.

This software product can be classified as a tool for group, in general, remote decision-making on ranking alternatives based on their ratings on several (two or more) criteria. The system does not provide loading software to individual workplaces of experts. All decision support work is done online. The PAPRIKA method is the cornerstone of mathematical support of the system [8], [9]. The method is based on pairwise ranking of all possible alternatives. In the process of working with the system, experts are encouraged to compare pairwise alternatives. Provided that a given set is considered. In the conversational mode, experts answer the question: "Which of the two alternatives is preferable?'. Usually, it is about reaching a compromise between several criteria.

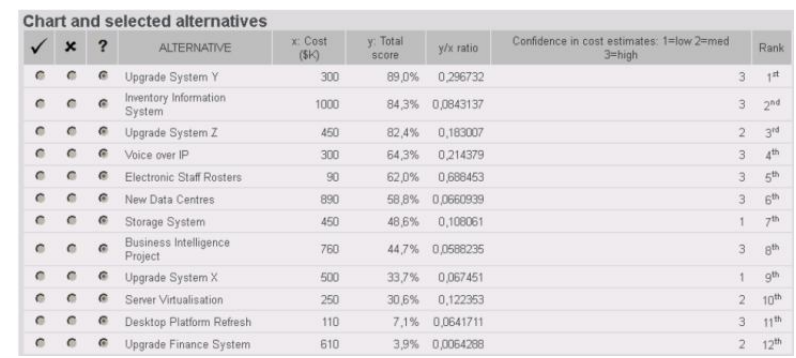

Figure 1. General view of the DSS interface 1000minds

For example, an expert is invited to choose a promising project for investment, but a very expensive or less promising project, but with a smaller amount of investment resources. There can be more than two criteria. The order of pairwise comparisons is chosen so as to minimize the number of calls to the expert. The final outcome of the evaluation is a rating and ranking of alternatives. Figure 1 shows a table with a ranking of innovative projects in the field of information technology, built using the 1000 minds system.

A similar tabular approach of presenting results in the DS process in investing into cybersecurity systems is used in the DMSSCSE software product [10]-[13], see Figure 2.

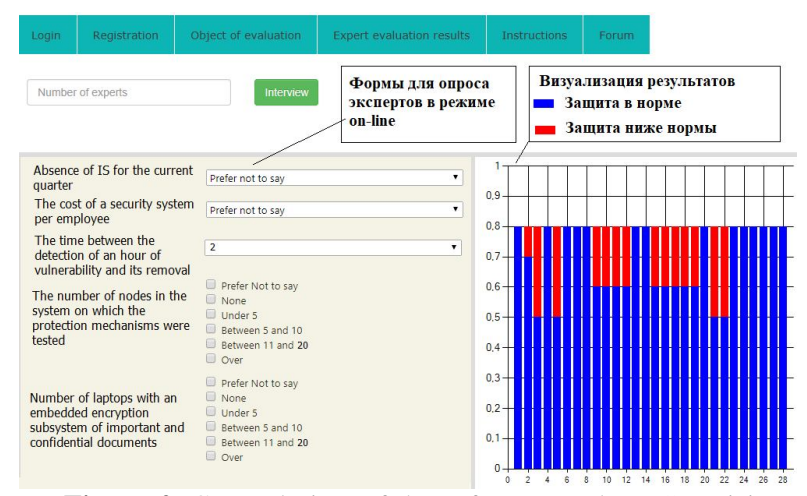

Figure 2. General view of the software package "Decision Support System for Enterprise Cybersecurity Management DMSSCSE" (for on-line experts)

The "Analysis" software package uses a visual approach to present the problem being solved. The "Analysis" package was developed by Lumina Decision Systems [14]-[15]. DSS allows illustratively represent the situation that requires a decision. So-called activity diagrams are used to visualize the situation during the decision and the DS, see Figure 3.

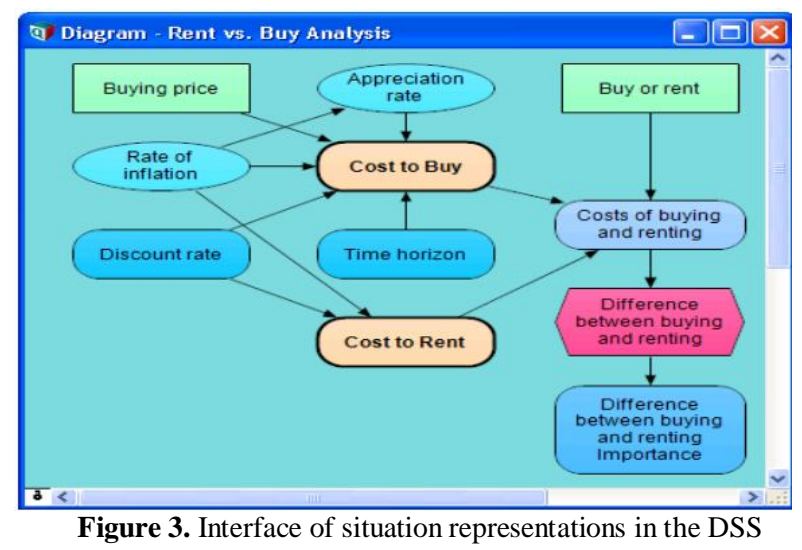

«Analysis»

Nodes in an impact diagram can be of one of the following types:

Decision (parameter controlled by the user or decision maker);

Chance (parameter with probabilistic character);

Objective (the main purpose of the examination, (usually the only one), for example, to choose a more attractive and efficient investment project);

Variable (for example, the interest rate for the use of an investment resource);

Constraint (for example, maximum investment resources directed to a specific project);

Module (node uniting child nodes and diagrams necessary for decomposition of a large segment);

Index (parameter denoting the names of certain set elements, for example, the names of investment projects);

Constant (for example, time parameters of the project, 6, 9, 12 and more months);

Function (node that calls a user-defined function or whole library); 
Button (component to generate certain user-defined procedures (Script)).

It should be noted that the mathematical support of the "Analysis" system is not based on any specific methods of multi-criteria DS, but mainly on statistical tools. Considerable attention of developers is paid to constructing probability distribution functions for quantities that characterize alternatives in solutions. "Analysis" system is not intended to be used as a pair of comparisons. In the course of work with the "Analytics" package the expert only sets certain parameters and extreme values of the quantities that influence on achieving the ultimate goal of the examination. This is quite convenient in practice, but imposes restrictions on the types of tasks to be solved.

The D-Sight DSS [8], [16] is distinguished by a fairly friendly interface and an acceptable level of functionality. This software product is designed for multi-criteria evaluation (ranking) of a variety of alternatives using different scales. As a scale, you can choose - quantitative or/and qualitative evaluation criteria, see Figure 4 a. An interesting opportunity of the expert to form his own scale should be noted. For example, when choosing a person responsible for the implementation of a project, you can choose according to the applicant's professional skills, see Figure 4 b. During the examination, as in most other DSS, we can set the values of estimate alternatives and criteria weights. There are many means of visualizing the results in "D-Sight", which makes it quite convenient for a starting expert.

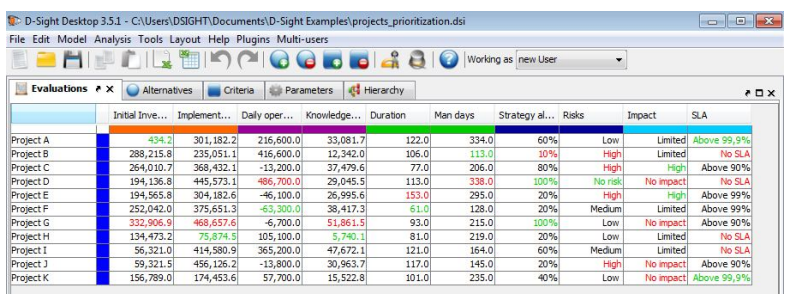

a) choosing priority investment projects in "D-Sight"

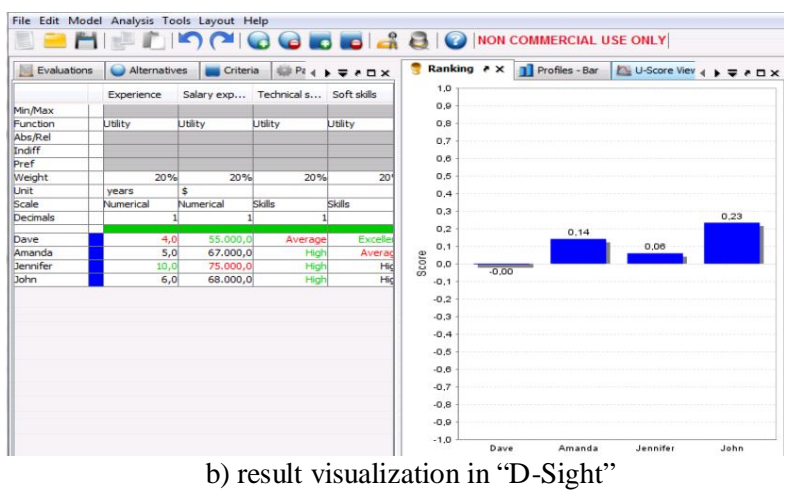

Figure 4. General view of the "D-Sight" DSS interface

The popular MakeItRational DSS is implemented by developers based on the hierarchy analysis method [17]. The system is designed for multi-criteria evaluation and selection of alternatives from a given set. First, a variety of alternatives are introduced, then a global evaluation criterion. Then the hierarchy of subcriteria is set. The system displays both negative and positive impacts (for example, costs and profits during the implementation of an investment project). At the next stage, alternatives are evaluated according to various criteria. Note that the estimates can be set directly, in the form of numerical values, or in the form of pairwise comparisons in the Saaty scale [8]. The final result of the examination is the ranking of alternatives according to global criteria. The interface view of this DSS is shown in Figure 5. There is a possibility of results' export to MS Excel and automating the formation of a document with a final report on the results of the examination.

The «MindDecider» DSS [18], as well as the other systems considered in this article, is intended for multicriteria evaluation and building alternatives rating. The examination is divided into several stages, each with a specific operation mode: planning and design, evaluation, time analysis, report generation. First, the main goal is formed, then - many alternatives, evaluation criteria and ranges of evaluation values. Later, alternatives are evaluated by criteria. After aggregating the alternatives evaluation of according to individual criteria, their global rating (in percentage) and global ranking are constructed. An example of the system interface is shown in Figure 6

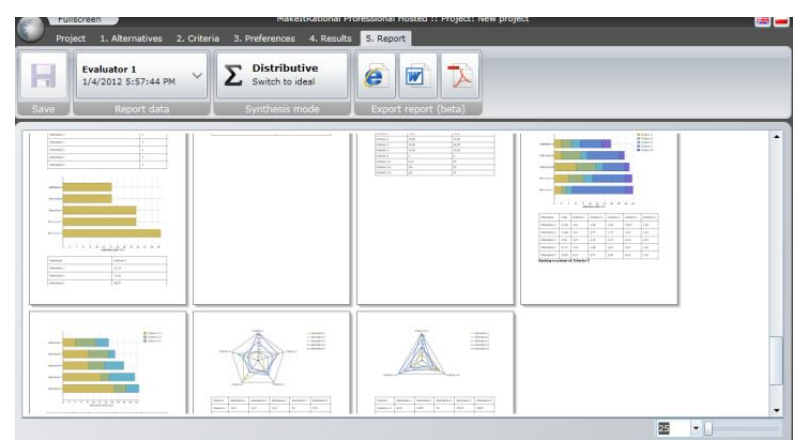

Figure 5. General view of the «MakeItRational» DSS interface

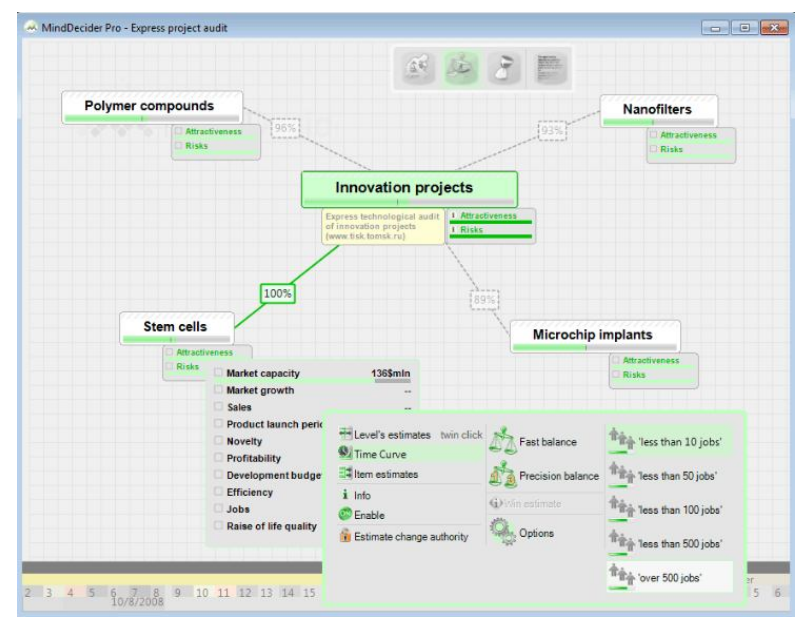

Figure 6. General view of the «MindDecider» DSS interface

«Logical Decisions» DSS [19] uses the tools of the hierarchy analysis method. The system is designed for multi-criteria evaluation of alternatives from a given set. Weights of criteria are set by direct estimation, or pairwise 
comparisons for an arbitrary scale. Alternatives are evaluated in pairs, again, on an arbitrary scale. Figure 7 shows a view of the criteria hierarchy and the ranking of 3 alternatives by these criteria in the decision support process.

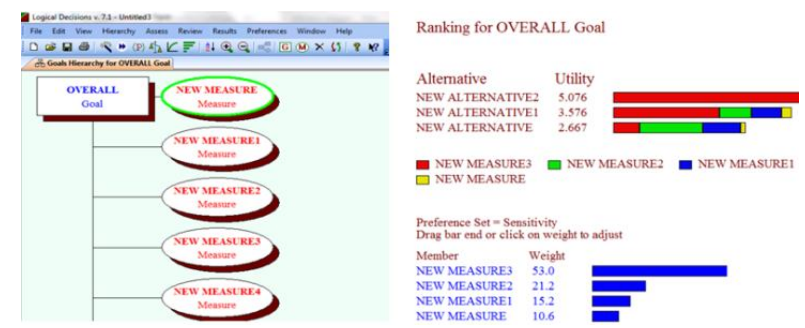

Figure 7. General view of the DSS «Logical Decisions» interface and the results of the examination

Not dwelling on individual software products belonging to the category of DSS, and the methods that underlie their software, we turn our attention to the criteria by which modern DSS is compared, see Table 1 . As we see, the general requirements for the DSS provide the following possibilities: introduction of evaluations in the form of comparisons, analysis of the solution's "sensitivity" to changes in the criteria weights and evaluation values, conducting group examinations and working in remote mode.

Despite that there is no official standards of DSS development, it is possible to quite clearly highlight the necessary requirements for such systems, guided by common sense and their main functions.

Table 1. Comparative analysis of DSS

\begin{tabular}{|l|c|c|c|c|c|}
\hline \multicolumn{1}{|c|}{ DSS } & $\begin{array}{l}\text { Paired } \\
\text { compa } \\
\text { rison }\end{array}$ & $\begin{array}{l}\text { Time } \\
\text { analy- } \\
\text { sis }\end{array}$ & $\begin{array}{l}\text { Clus- } \\
\text { ter } \\
\text { evalua } \\
\text { tion }\end{array}$ & $\begin{array}{l}\text { Risk } \\
\text { eva- } \\
\text { lua- } \\
\text { tion }\end{array}$ & $\begin{array}{l}\text { Possi- } \\
\text { bility of } \\
\text { working } \\
\text { On-line }\end{array}$ \\
\hline 1000 minds & + & - & + & - & + \\
\hline DMSSCSE & - & - & + & - & + \\
\hline Analysis & - & + & - & + & + \\
\hline D-Sight & + & - & + & + & + \\
\hline $\begin{array}{l}\text { MakeItRation } \\
\text { al }\end{array}$ & + & - & + & - & + \\
\hline MindDecider & + & + & + & + & - \\
\hline $\begin{array}{l}\text { Logical } \\
\text { Decisions }\end{array}$ & + & - & + & + & - \\
\hline $\begin{array}{l}\text { Expert } \\
\text { Choice }\end{array}$ & + & - & + & + & + \\
\hline $\begin{array}{l}\text { SuperDeci- } \\
\text { sions }\end{array}$ & + & - & - & + & - \\
\hline TreeAge Pro & + & - & - & + & - \\
\hline $\begin{array}{l}\text { EVALUA- } \\
\text { TION AND } \\
\text { SELECTION }\end{array}$ & + & - & + & + & - \\
\hline
\end{tabular}

Although the review in this section of the article cannot be considered exhaustive, it illustrates the most common trends in the development of modern DSS.

On the basis of the existing DSS's review, in particular, in the tasks of evaluating the investment attractiveness of projects, it can be concluded that group examination is an essential requirement for collaborating with experts in modern DSS. Unfortunately, at the present time possibility of the system maintenance (its knowledge base - KB) during long-term operation, giving experts ability to change their previous judgments by DSS developers is practically not provided [17]-[19]. Considering the abovementioned limitations of the existing DS and DSS technologies, there is an urgent task to develop decisionmaking tools for various purposes, which will allow to get, interpret, process, approve and aggregate more efficient and correct individual expert evaluation.

\section{Paradigms for attractive DSS in INVESTMENT PROJECTS EVALUATION IN THE FIELD OF ENTERPRISE DIGITALIZATION}

In many cases, investing in innovative projects, for example, in the field of enterprise digitalization, is characterized by a high degree of uncertainty and riskiness. Today data analysis "intelligent" systems are used in increasing frequency in order to increase the effectiveness and optimize the procedure of project evaluation and decision-making connected with investment [10]-[13], [16]. The DSS, discussed in the previous section of the article, have shown good results.

Filling the DSS and their separate modules, which are directly responsible for the analysis and solution of problems, is carried out by introducing blocks containing programmed algorithms for economic and mathematical models. However, not many DSSs allow optimizing procedures related to finding different variant strategies. Graphical visualization of analysis results also remains problematic. This can immediately give the investor a clear understanding prospects of investing in the project.

Two paradigms are the basis of the research and development of tools for perspective DSS in the problems of investing in enterprises in the field of digitalization.

The first is that for each elementary assessment the expert is offered a scale that is most appropriate to his knowledge of the subject matter, for example, in the field of evaluating the investment attractiveness of a project.

The second paradigm is that there is no absolute equivalence when comparing alternatives. According to this paradigm - there is no absolute equivalence when comparing objects. In such cases, if the expert tends to think about the equivalence of objects, this indicates a lack of knowledge to distinguish between such objects.

Previously obtained results of the study [20], [21] allowed to determine the general principles of DSS design for choosing an effective investment strategy and project evaluation in the field of digitalization. We have also identified a number of tasks that need to be addressed to achieve this goal. These tasks form the basis of an integrated information processing system in the DSS, that can be represented as a sequence:

$$
A=\langle A I P, A R P, U I, F I P, V N D T, O P T, E D\rangle .
$$
2.

The content of sequence elements (1) is given in Table 
Table 2. Sequence parameters of the DSS tasks' subsystem for evaluating investment projects

\begin{tabular}{|c|c|l|}
\hline $\mathrm{N}$ & Notation & $\begin{array}{l}\text { Content of the sequence elements (problem } \\
\text { solved/current task) }\end{array}$ \\
\hline 1 & $A I P$ & $\begin{array}{l}\text { Analysis of the enterprise's investment } \\
\text { potential }\end{array}$ \\
\hline 2 & $A R P$ & Analysis of the enterprise's resource potential \\
\hline 3 & $U I$ & $\begin{array}{l}\text { Identification of the "qualitative" investment } \\
\text { objects set }\end{array}$ \\
\hline 4 & $F I P$ & $\begin{array}{l}\text { Formation of investment projects set in the } \\
\text { field of enterprise digitalization }\end{array}$ \\
\hline 5 & $V N D T$ & $\begin{array}{l}\text { Selection of the best available technologies } \\
\text { for enterprises of investment objects }\end{array}$ \\
\hline 6 & $O P T$ & $\begin{array}{l}\text { Optimization of investment resources } \\
\text { distribution }\end{array}$ \\
\hline 7 & $E D$ & $\begin{array}{l}\text { Formation of a report on economic efficiency } \\
\text { of investment activities }\end{array}$ \\
\hline
\end{tabular}

The purpose of the sequence elements will be considered in more detail.

1. The problem of digitalization sphere enterprise's investment potential analysis $(A I P)$ allows investors to make a management decision on the appropriateness of the investment.

In the process of solving the fulfillment of risk acceptability conditions arising from possible loss of funds or failure to achieve the expected economic effect, for example, with an unsatisfactory financial provisions of the enterprise is considered.

2. The problem of analyzing the enterprise's resource and ecological potential ( $A R P$ ). Having solved it, we will get an integrated assessment of the existing influence of enterprises on the economy of the region.

3. The problem of identification of the "qualitative" investment objects set $(U I)$ is related to the formation of an optimal investment portfolio of enterprises in the field of digitalization.

4. The problem of forming an investment projects set in the field of enterprise digitalization (FIP) is solved using a specific mechanism of evaluating the economic efficiency of investment projects using a system of special indicators [4], [6], [8], [16].

5. The problem of selecting the best available technologies for enterprises of investment objects (VNDT ) allows a certain enterprise in the field of digitalization to determine the best investment project from a variety of alternative.

6. The problem of optimal distribution of limited investment resources $(O P T)$ among enterprises, for example, the region. As a result of the decision, we determine the amount of investments that need to be allocated to a particular enterprise in the field of digitalization, achieving the maximum total economic efficiency from investing in all selected enterprises.

7. The problem of forming a report on economic efficiency of investment activities and forming an archive of previous options of projects calculation and evaluation ( $E D$ ).

Solving the formulated problems using appropriate models (for example, those considered in [16], [20], [21]) involves the use of various methods of analysis and synthesis. Most of the methods are already used in the DSS software implementations considered above. The set of the used methods can be presented in a sequence form:

$$
M I F=\langle M S, M E O, M L P, M D P, M E I\rangle .
$$

Content of the sequence elements (2) is presented in Table 3.

Table 3. Sequence parameters of the subsystem analysis methods in the DSS for evaluating investment projects

\begin{tabular}{|c|c|l|}
\hline N & Notation & \multicolumn{1}{|c|}{$\begin{array}{c}\text { Content of the sequence elements } \\
\text { (Methods) }\end{array}$} \\
\hline 1 & $M S$ & $\begin{array}{l}\text { Formalized methods of analyzing the } \\
\text { state of the enterprise in the field of } \\
\text { digitalization }\end{array}$ \\
\hline 3 & $M L P$ & $\begin{array}{l}\text { Analysis based on expert evaluation and } \\
\text { game theory }\end{array}$ \\
\hline 4 & $M D P$ & Linear programming \\
\hline 5 & $M E I$ & $\begin{array}{l}\text { Dynamic programming formalized methods of } \\
\text { determining the efficiency of } \\
\text { investment activities (theory of fuzzy } \\
\text { logic, neural networks, etc.) }\end{array}$ \\
\hline
\end{tabular}

Thus, sequences (1) and (2), in accordance with the problems and methods of analysis, form subsystems within the computation block/calculation block of the DSS in the process of modeling an effective investment policy in enterprises in the field of digitalization (Figure 8).

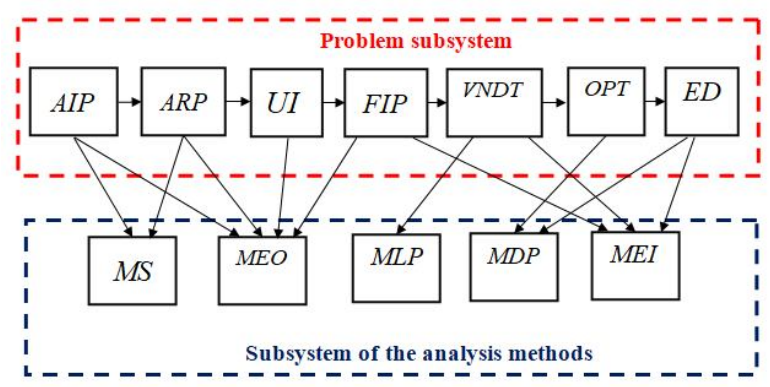

Figure 8. Computation block/calculation block of perspective DSS for investment evaluation problems

Table 4 presents the results of the generalization during the analysis of existing problem-oriented application packages, which in some cases allow computational experiments for a specific task sequence.

Table 4 - Analysis of information technologies used to develop DSS modules

\begin{tabular}{|c|c|c|c|}
\hline No & $\begin{array}{c}\text { Subsystem } \\
\text { of } \\
\text { problems }\end{array}$ & $\begin{array}{l}\text { Subsystem } \\
\text { of methods }\end{array}$ & $\begin{array}{c}\text { Application } \\
\text { programs }\end{array}$ \\
\hline 1 & $A I P$ & $\begin{array}{l}M S \\
M E O\end{array}$ & $\begin{array}{l}\text { Project } \\
\text { AnalyzerXL, } \\
\text { InvestWork } \\
\text { 1000minds, } \\
\text { DMSSCSE, Analysis, } \\
\text { D-Sight, } \\
\text { MakeItRational, } \\
\text { MindDecider, Logical }\end{array}$ \\
\hline
\end{tabular}




\begin{tabular}{|c|c|c|c|}
\hline & & & $\begin{array}{l}\text { Decisions, } \\
\text { Choice, } \\
\text { SuperDecisions, } \\
\text { TreeAge } \\
\text { "OTSENKA } \\
\text { VYBOR", } \\
\text { "Investitsionnyj analiz } \\
\text { 1.7" and etc. }\end{array}$ \\
\hline 2 & $A R P$ & $M S, M E O$ & Need to be developed \\
\hline 3 & $U I$ & $M E O$ & Need to be developed \\
\hline 4 & FIP & $\begin{array}{l}M E O, \\
M E I\end{array}$ & Need to be developed \\
\hline 5 & VNDT & $\begin{array}{c}M L P, \\
M E I\end{array}$ & $\begin{array}{l}\text { MS Excel, MatLab, } \\
\text { MathCAD } \\
\text { STATISTICA, and } \\
\text { etc. }\end{array}$ \\
\hline 6 & $O P T$ & $\begin{array}{l}M D P \\
M E I\end{array}$ & $\begin{array}{ll}\text { Scilab, } & \text { ST } \\
\text { NeuralNetworks } & \end{array}$ \\
\hline 7 & $E D$ & $\begin{array}{c}M D P \\
M E I\end{array}$ & $\begin{array}{l}\text { Scilab, ST } \\
\text { NeuralNetworks }\end{array}$ \\
\hline
\end{tabular}

At the same time application programs listed in Table 4, as well as DSS, described above in the article (see Table 1), can cover a fairly large range of problems, for example, to determine a rational investor strategy for mutual investment, with incomplete information about project partners, etc. However, not all problems as shown above, can be successfully solved on the basis of existing software products.

Thus, the problem of implementing an applied software package seems to be perspective, that will make it possible to take into account these drawbacks. In order to create an effective DSS, it is necessary to form an integrated information processing system, implement a data control unit and develop a convenient user interface control unit, see Figure 9.

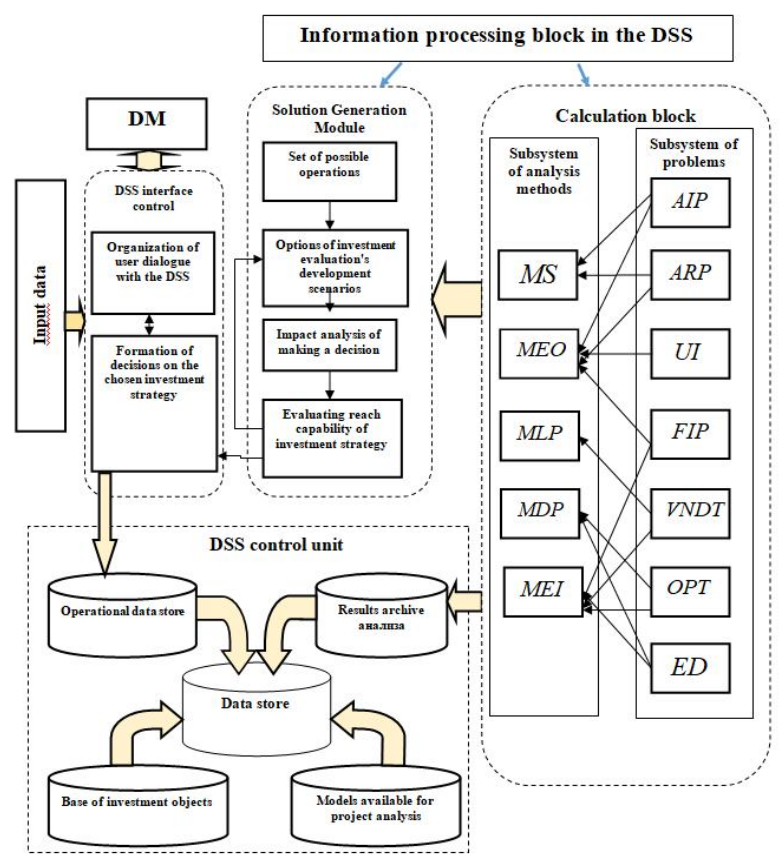

Figure 9. The functional structure of the DSS for evaluation of investment projects in the field of enterprise digitalization
Let us briefly consider the main problems, the solution of which is placed upon the individual blocks of the designed DSS:

1. Computation unit. Its functional purpose is described above in Tables 2 and 3.

2. The DSS interface control unit is intended to solve such problems:

- supporting the dialogue between the system and the user;

- regulation and distribution of information flows between blocks;

- providing the information requested by the user.

3. The DSS data control unit is meant to solve these problems:

- information storage;

- various manipulations with existing data (updating, deletion, addition, etc.);

- providing information upon request of the user and combining information from various sources.

The data generated in the calculation block (CB), as well as the indicators describing the situation, are transmitted to the next module where (strategies) are generated. Appropriate calculations are made when elaborating investment strategies. Further, all information obtained during the development of strategies and calculations is recorded in the database, including a list of operations. Rational investor strategies can be generated on the basis of these data, as well as data obtained at other values of $\mathrm{CB}$ parameters. Thus, all possible scenarios are modeled and then the problem of choosing the best one arises. Analysis of alternatives involves the use of other methods, for example, fuzzy logic, game theory, etc.

After the evaluation procedure of investment scenarios has been carried out, two options are possible. In the first case, we proceed to evaluating reach capability of investment strategy. In the second case, if no satisfactory solutions are found, we search for another alternative.

At the last stage of the DSS operation the final decision and reporting are made.

\section{CONCLUSIONS}

The following conclusions were made on the basis of the research done as part of the article:

- it has been shown that to increase the reliability of recommendations provided to decision makers (DM) in various fields, in particular, in problems related to the evaluation of investment projects, it is necessary to introduce and make more extensive use of computer systems and software products related to decision support systems (DSS);

- it has been shown that in order to increase the efficiency of the decision support process it is necessary to develop new models and methods for expert evaluation of decision support (DS) and appropriate software tools on their basis that will allow to get, process, harmonize and summarize individual expert assessments more efficiently. This ultimately contributes to the provision of more reliable recommendations to the decision maker in the course of solving practical problems;

- the essence of the proposed paradigms on which these perspective software developments should be based has been disclosed. In accordance with the stages of 
information processing in the course of DSS, the main tasks have been formulated that must be solved in the process of synthesizing the theoretical and softwaretechnological bases for creating the corresponding DSS toolkit in high-level languages;

- a general methodology has been proposed for the subsequent stages of research and the use of the necessary mathematical apparatus to achieve the final goals development of DSS for evaluating investment projects in the field of enterprise digitalization.

\section{REFERENCES}

1. http://economy.gov.kz/ru/pages/gosudarstvennayaprogramma-cifrovoy-kazahstan-na-2017-2020-goda

2. Lee, In, and Kyoochun Lee, The Internet of Things (IoT): Applications, investments, and challenges for enterprises, Business Horizons, 58.4, pp. 431440, 2015.

3. Tjader, Youxu, et al, Firm-level outsourcing decision making: A balanced scorecard-based analytic network process model, International Journal of Production Economics, 147, pp. 614-623, 2014.

4. Huang, C. Derrick, Ravi S. Behara, and Jahyun Goo, Optimal information security investment in a Healthcare Information Exchange: An economic analysis, Decision Support Systems, 61, pp. 1-11, 2014.

5. D.J. Power, Decision support systems: concepts and resources for managers, Westport, Conn.: Quorum Books, 2002, 251p.

6. A. Fielder, E. Panaousis, P. Malacaria, C. Hankin \& F. Smeraldi, Decision support approaches for cyber security investment, Decision Support Systems, 86, pp. 13-23, 2016.

7. B. Mareschal, J.-P.Brans, "PROMETHEE Methods", Ch 5 in: J. Figueira, S. Greco and M. Ehrgott, eds, Multiple Criteria Decision Analysis: State of the Art Surveys Series, New York: Springer, 2005.

8. V.L. Sauter, Decision support systems for business intelligence, John Wiley \& Sons, 2014.

9. R. Sharda, D. Delen, E. Turban, J. Aronson \& T. Liang, Businesss Intelligence and Analytics: Systems for Decision Support-(Required), London: Prentice Hall, 2014.

10. B. Akhmetov, V. Lakhno, B. Akhmetov, Z. Alimseitova, Development of sectoral intellectualized expert systems and decision making support systems in cybersecurity, Advances in Intelligent Systems and Computing, Vol. 860, pp. 162-171, 2019. DOI: 10.1007/978-3-03000184-1_15

11. V. Lakhno, B. Akhmetov, A. Korchenko, V. Grebenuk, Z. Alimseitova, Development of a decision support system based on expert evaluation for the Situation Center of Transport Cybersecurity, Journal of Theoretical and Applied Information Technology, Vol. 96, № 14, pp. 4530-4540, 2018.

12. B. Akhmetov, V. Lakhno, V. Malyukov, S. Sarsimbayeva, M. Zhumadilova, T. Kartbayev, Decision support system about investments in smart city in conditions of incomplete information,
International Journal of Civil Engineering and Technology, 10 (2), pp. 661-670, 2019.

13. B.S. Akhmetov, V.A. Lakhno, V.P. Malyukov, A.A. Doszhanova, Zh.K Alimseitova, Adaptive Model of Cybersecurity Financing with Fuzzy Sets of Threats and Resources at the Protection Side, International Journal of Advanced Trends in Computer Science and Engineering (IJATCSE), Vol. 9, No.4, pp. 5046-5052, 2020 https://doi.org/10.30534/ijatcse/2020/124942020,

14. V.A. Lakhno, M.V. Lakhno, K.T. Sauanova, Sh.N. Sagyndykova, S.A. Adilzhanova, Decision support system on optimization of information protection tools placement, International Journal of Advanced Trends in Computer Science and Engineering (IJATCSE), Vol. 9, No.4, pp. 4457-4464, 2020 https://doi.org/10.30534/ijatcse/2020/39942020

15. E. W. T. Ngai, S. Peng, P. Alexander \& K.K. Moon, Decision support and intelligent systems in the textile and apparel supply chain: An academic review of research articles. Expert Systems with Applications, 41(1), pp. 81-91, 2014.

16. A. Kumar, B. Sah, A.R. Singh, Y. Deng, X. He, P. Kumar \& R.C. Bansal, A review of multi criteria decision making (MCDM) towards sustainable renewable energy development, Renewable and Sustainable Energy Reviews, 69, pp. 596-609, 2017.

17. M.M. de Brito, M. Evers, Multi-criteria decisionmaking for flood risk management: a survey of the current state of the art. Natural Hazards and Earth System Sciences, 16(4), pp. 1019-1033, 2016.

18. H.R. Weistroffer, Y. Li, Multiple criteria decision analysis software. In Multiple Criteria Decision Analysis, pp. 1301-1341, 2016.

19. C. Thirumalai, M. Senthilkumar, An Assessment Framework of Intuitionistic Fuzzy Network for C2B Decision Making, In Electronics and Communication Systems (ICECS), 4th International Conference on, pp. 164-167, 2017.

20. B. Akhmetov, L. Kydyralina, V. Lakhno, G. Mohylnyi, J. Akhmetova, A. Tashimova, Model for a computer decision support system on mutual investment in the cybersecurity of educational institutions, International Journal of Mechanical Engineering and Technology, Vol. 9, Iss. 10, pp. 1114-1122, 2018.

21. V. Lakhno, B. Akhmetov, V. Malyukov, T. Kartbaev, Modeling of the decision-making procedure for financing of cyber security means of cloud services by the medium of a bilinear multistep quality game with several terminal surfaces, International Journal of Electronics and Telecommunications, Vol. 64, Iss. 4, pp. 467-472, 2018. 